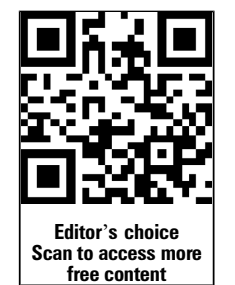

free content
- Additional material is published online only. To view please visit the journal online (http://dx.doi.org/10.1136/ emermed-2012-201099).

1 Departments of Surgery, Academic Medical Center, Amsterdam, The Netherlands ${ }^{2}$ Quality Assurance \& Process Innovation, Academic Medical Center, Amsterdam,

The Netherlands ${ }^{3}$ Amsterdam School of Health Professions, Amsterdam, The Netherlands ${ }^{4}$ Department of Emergency Medicine, Medical Center Alkmaar, Alkmaar, The Netherlands ${ }^{5}$ Department of Emergency Medicine, Academic Medical Center, Amsterdam,

The Netherlands

\section{Correspondence to} Marja N Storm-Versloot, Department of Surgery, G3-151, Academic Medical Center, Meibergdreef 9, P.O. Box 22700, Amsterdam 1100 DE, The Netherlands; m.n.storm@amc.uva.nl

Received 4 January 2012 Revised 9 November 2012 Accepted 5 December 2012 Published Online First 9 January 2013

\footnotetext{
To cite: Storm-Versloot MN, Vermeulen $\mathrm{H}$, van Lammeren $\mathrm{N}$, et al. Emerg Med J 2014;31:13-18.
}

\title{
Influence of the Manchester triage system on waiting time, treatment time, length of stay and patient satisfaction; a before and after study
}

\author{
Marja N Storm-Versloot, ${ }_{1}^{1}$ Hester Vermeulen, ${ }^{2,3}$ Nienke van Lammeren, ${ }^{4}$ \\ Jan SK Luitse, ${ }^{1,5}$ J Carel Goslings ${ }^{1}$
}

\begin{abstract}
Objectives To compare waiting time, treatment time, length of stay (LOS), patient satisfaction and distribution of waiting times over levels of urgency before and after the implementation of the Manchester Triage system (MTS) at an emergency department (ED).
\end{abstract}

Methods Before and after study, by means of timeline measurements and questionnaires on satisfaction in two consecutive patient series ( $n=1808)$. Questionnaires covered aspects of provision of information, opportunity given to explain problems, waiting time and sorting out the problem. After implementation of MTS, patients were triaged between 12:00 and 22:00. Subanalysis was performed on triaging and non-triaging; and between urgency levels.

Results Waiting time did not decrease after implementation of the MTS, however, treatment time and LOS were significantly longer. Total LOS did not differ. After implementation, waiting time was better distributed over urgency levels.

Furthermore, after implementation, patient satisfaction scored significantly lower on the provision of information and opportunity to explain their problems, however, waiting time and the feeling that their problem had been sorted out scored better. No significant differences were found between triaged and non-triaged patients. Although not significant, patients in the lower urgency levels seemed more satisfied than patients in the higher urgency levels.

Conclusions Implementing MTS on its own is not sufficient to improve efficiency and quality of EDs. More complex interventions including process redesigning that targets various groups of ED patients should be evaluated in the future by using rigorous research designs for quality improvement of EDs.

\section{INTRODUCTION}

Annually, more than two million people attend Dutch hospital emergency departments (ED). An increasing number of patients are bypassing the general practitioner (GP) and attending with nonurgent problems. This has caused overcrowding at the $\mathrm{ED}^{1}$ which has become a serious problem leading to long waiting times, patient dissatisfaction $^{2}$ and putting patients at risk for poor outcome. $^{3}{ }^{4}$ For these reasons, the implementation of accurate triage systems at EDs is advocated. ${ }^{5}$

Although actual waiting time is important, it is perceived as waiting time which is strongly correlated with patient satisfaction. ${ }^{6}$ Patient satisfaction may seem to be a secondary outcome, but it is important, as satisfied patients are more likely to comply with treatment and, therefore, achieve better clinical outcomes than dissatisfied patients. ${ }^{7}$ Consequently, in recent decades, patient perception of quality of care at an ED has become an increasingly important concept in continuous quality improvement. ${ }^{6} 8$

Patient satisfaction, waiting time and length of stay (LOS) relating to the Emergency Severity Index and the Canadian Emergency Department Triage and Acuity Scale, ${ }^{9}{ }^{10}$ have all been studied, but to our knowledge, no studies on the Manchester Triage System (MTS) have been published on patient satisfaction. In previous research, we reported on validity and accuracy, for example, the relationship of triage ratings with different patient outcomes. ${ }^{11} 12$ Following these results, the MTS was implemented at our hospital in October 2007. The MTS uses flowcharts, which are based on a five-step decision process, to assign patients to one of five triage categories. $^{13}$ A colour indicates the level of urgency and its associated maximum waiting time: red, immediate care by a physician; orange, $10 \mathrm{~min}$; yellow, $60 \mathrm{~min}$; green, $2 \mathrm{~h}$ and blue, $4 \mathrm{~h}$.

The objective of this study was to compare waiting time, treatment time, LOS, patient satisfaction and distribution of waiting times over the levels of urgency, before and after the implementation of the MTS.

\section{METHODS}

Study design, study setting and population

In this prospective, single-centre, 'before' and 'after' study, we compared waiting time, treatment time, LOS and patient satisfaction. The study was carried out in The Netherlands at a university teaching hospital with a Level 1 trauma centre. Annually, more than 31000 patients attend this hospital's ED, 750 (2\%) of whom are seen in the trauma resuscitation room. Approximately 2 years before the implementation of the MTS, 906 consecutive patients were included over a 10-day period. Six months after the implementation of the MTS, a further 900 consecutive patients were included. The local institutional review board waived the requirement for written informed consent from the patients.

\section{Implementation of the MTS}

Before implementation of the MTS in October 2007, an informally structured triage system was used. This system was based on clinical expertise, but not on explicit criteria and information. When registered at the ED, based on patients' appearance 
and presenting complaints, patients were (implicitly) judged by the ED nurse or an experienced receptionist if they could wait safely or have to be seen immediately. All registered ED nurses received a combination of didactic and practical training in the MTS, in accordance with national standards. After implementation of the MTS, patients arriving at the ED between 12:00 and 22:00 were triaged. This group comprised $70 \%$ of all patients attending the ED over a $24 \mathrm{~h}$ period. Outside these times, patients were registered and implicitly judged by an ED nurse, and when necessary, the nurse triaged patients according to the MTS. Patients already triaged before hospital arrival by ambulance staff (following their own protocols), were not triaged again, but placed in the treating room according local guidelines.

\section{Study protocol}

\section{Data collection and definitions}

We collected the following patient data: patient characteristics, mode of arrival, mode of referral, triage ratings by a triage nurse and admission to hospital. Timeline information was extracted from ED forms. Times recorded routinely were: time of registration, time of start of triage, time to treatment and time of leaving ED. These were issueemented with time from arrival at the ED, and time leaving the triage room. Patients entered this additional information onto an extended time measurement form. Arrival time was defined as the time from arrival at ED to registration; waiting time as the time in minutes from registration to entering the treatment room; time to triage as the time from registration to triage; triage time as the time from start triage to end triage; triage to treatment as the time from end triage to entering the treatment room; treatment time as the time from entering the treatment room to discharge or admission; the LOS as the time from registration to discharge or admission. Following local guidelines, diagnostic procedures (eg, blood samples) were started before seeing a doctor. Therefore, 'time entering the treatment room' seems more accurate and closer to real-life practice than 'time seeing a doctor'.

\section{Informed consent and patient instruction}

In both measurements, on arrival at the department, patients were given an information letter and asked to participate. After giving oral consent, they received a numbered patient form, a watch and a pencil and instructions about how to participate. To prevent patients becoming confused between triage and treatment, the patient form included a clear explanation and photographs of the triage room. The patient was asked to return the completed form to the receptionist on leaving the ED. If the patient refused or was unable to fill in the form, only the routinely recorded time points from the ED forms was used.

\section{Patient satisfaction}

To measure patient satisfaction, four questions were asked that reflected identified service-related factors during their ED stay. ${ }^{14} 15$ Patients were asked to rate: (1) the spoken information they received before they were seen or treated by a doctor, (2) the opportunity they were given to explain their problems, (3) the length of waiting time and (4) the feeling that their complaint or problem had been sorted out. This was done on a five-point Likert-type scale; very satisfied, satisfied, reasonably satisfied, fairly satisfied and not satisfied. In the before implementation group, patients answered these four questions at the ED. In the after implementation group, these four questions made up part of a more extensive questionnaire on patient satisfaction. This questionnaire was not filled out at the ED but handed over to be completed at a later time. Patients were asked to fill out this questionnaire and return it within 2 weeks. If patients were not given the questionnaire, it was sent by post. Reminders were sent within a month.

\section{Data analysis}

Data were analysed using SPSS V.14.0, (Chicago, Illinois, USA). Patient characteristics were reported descriptively. The $\chi^{2}$ test was used for categorical data, the independent sample two-tailed $t$ test for normal, continuous data, the Mann-Whitney test or the Kruskal-Wallis test for non-normally distributed data, to compare the before and after implementation data. The level of significance was 0.05 .

Subanalysis of timeline data was carried out on mode of referral, mode of arrival, triaging and non-triaging of patients; and between the urgency levels of the patients triaged. In triaged patients, we also determined the number of patients who after being triaged entered the treatment room within the maximum waiting time defined by the MTS. ${ }^{13}$

These comparisons were defined a priori. Exploring differences in timeline data; type 2 errors are not warranted, therefore, the Bonferroni test was not considered to correct for multiple comparisons. ${ }^{16}$

To compare patient satisfaction scores, we re-expressed the Likert scale into three levels for the ratings: very satisfied and satisfied, became satisfied; reasonably satisfied and fairly satisfied, became fairly satisfied and not satisfied, remained the same. Subanalysis of satisfaction data was performed on triaging and not triaging, and between the urgency levels of the patients triaged.

\section{RESULTS}

\section{Patient characteristics and response rate}

Before implementation, 907 patients were included, and after implementation, 901. Five ED forms were incomplete, and thus excluded: one in the before implementation group and four in the after implementation group. Gender, age, mode of arrival, admission rate and patients already triaged by ambulance staff before arrival at hospital did not differ between groups, although age distribution did differ. Triaged patients only included those who arrived by private vehicle. In the after implementation group, significantly more patients were presented by their GP (table 1).

In the before implementation group, 356 (39.3\%), and in the after implementation group, 286 (31.9\%) patients completed the patient satisfaction questionnaire. No significant differences were found in sex, admission and mode of arrival between responding and non-responding patients.

\section{Waiting time, treatment time and LOS}

Before versus after implementation

Waiting time did not differ between before and after implementation of the MTS, but arrival time, treatment time and total LOS did (table 2). If a distinction was made for mode of referral, arrival time in self-referred and in GP-referred patients remained significant, as did the LOS in self-referred patients. For mode of arrival and arrival time, treatment time and LOS remained significant in patients arriving by private vehicle, but not in patients arriving by ambulance.

Waiting time from registration to the treatment room was longer for triaged than for non-triaged patients, but treatment time was shorter. Total LOS did not differ (table 3). 
Table 1 Patient characteristics

\begin{tabular}{|c|c|c|c|c|c|c|c|c|}
\hline & \multicolumn{2}{|c|}{ Before $(n=906)$} & \multicolumn{2}{|c|}{ After $(n=897)$} & \multicolumn{2}{|c|}{$\begin{array}{l}\text { After triaged } \\
\text { patients }(n=310)\end{array}$} & \multicolumn{2}{|c|}{$\begin{array}{l}\text { After non-triaged } \\
\text { patients }(n=587)\end{array}$} \\
\hline & $\mathbf{n}$ & $\%$ & $\mathbf{n}$ & $\%$ & $\mathbf{n}$ & $\%$ & $\mathbf{n}$ & $\%$ \\
\hline \multicolumn{9}{|l|}{ Gender } \\
\hline Male & 494 & 55 & 453 & 51 & 168 & 54 & 285 & 46 \\
\hline \multicolumn{9}{|l|}{ Age } \\
\hline Median (year) & 36 & & 36 & & 32 & & 38 & \\
\hline Range (year) & $0-94$ & & 0-97 & & 0-91 & & $0-97$ & \\
\hline IQR (25-75) & $21-54$ & & $19-54$ & & $17-48$ & & $21-57$ & \\
\hline \multicolumn{9}{|l|}{ Age distribution } \\
\hline$<15$ years & 138 & 15 & 170 & 19 & 67 & 22 & 103 & 18 \\
\hline $15-30$ years & 226 & 25 & 214 & 24 & 80 & 26 & 134 & 23 \\
\hline $30-45$ years & 234 & 26 & 191 & 21 & 73 & 24 & 118 & 20 \\
\hline $45-60$ years & 154 & 17 & 167 & 19 & 57 & 18 & 110 & 19 \\
\hline $60-75$ years & 82 & 9 & 100 & 11 & 25 & 8 & 75 & 13 \\
\hline$>75$ years & 72 & 8 & 55 & 6 & 8 & 3 & 47 & 8 \\
\hline \multicolumn{9}{|l|}{ Mode of arrival } \\
\hline Private vehicle or otherwise & 749 & 83 & 749 & 84 & 308 & 99 & 441 & 75 \\
\hline By ambulance & 157 & 17 & 148 & 16 & 2 & 1 & 146 & 25 \\
\hline \multicolumn{9}{|l|}{ Mode of referral } \\
\hline Self-referral & 675 & 75 & 630 & 70 & 231 & 75 & 399 & 68 \\
\hline Referred by GP or otherwise & 231 & 25 & 267 & 30 & 79 & 25 & 188 & 32 \\
\hline Number of admissions & 160 & 18 & 191 & 21 & 37 & 12 & 154 & 26 \\
\hline
\end{tabular}

After, after implementation group; Before, before implementation group; GP, general physician.

If the urgency level was higher, the triage time was longer. Also, time from triage to the treatment room, waiting time, treatment time and LOS were associated with urgency level (table 3). After being triaged, the maximum waiting time per urgency level was only exceeded in three patients triaged to the green level (table 4).

\section{Patient satisfaction}

Based on the four service-related questions, in the before implementation group, patient satisfaction concerning the provision of information and the opportunity to explain their problems was significantly higher. Satisfaction with length of waiting time was significantly higher in the after implementation group, as was the level of satisfaction about the way that their problem had been sorted out (table 5).

No significant differences were found between triaged and non-triaged patients (table 5). Also, no significant differences were found between urgency levels in the triaged patients, although overall, patients in the green level scored higher satisfaction rates on all questions than patients in the yellow level (table 5).

\section{DISCUSSION}

After implementation of the MTS, waiting time was better distributed over urgency levels: patients in the highest level of urgency waited for a shorter time than patients in the lower levels. As expected, after implementation of the MTS, overall we found no important decrease in waiting time and LOS. Patient satisfaction was higher for waiting time and the feeling that their problem had been sorted out,, but lower for the provision of information and the opportunity to explain their complaint. Also, we detected a positive trend in the satisfaction rates of low-urgency patients. As this group is by far the largest group of patients attending EDs, this is relevant to modern ED

Table 2 Median waiting and throughput time: for before and after implementation groups

\begin{tabular}{|c|c|c|c|c|c|c|c|c|}
\hline & \multicolumn{2}{|c|}{ Entrance time (min-max) } & \multicolumn{2}{|c|}{ Waiting time (min-max) } & \multicolumn{2}{|c|}{ Treatment time (min-max) } & \multicolumn{2}{|c|}{ Length of stay (min-max) } \\
\hline & Before $n=469$ & After $n=353$ & Before $n=887$ & After $n=776$ & Before $n=844$ & After $n=690$ & Before $n=856$ & After $n=771$ \\
\hline Total & $0.05(0-0.38)^{*}$ & $0.02(0-0.27)^{*}$ & $0.10(0-2.31)$ & $0.12(0-3.30)$ & $1.06(0.01-9.05)^{*}$ & $1.20(0-12.30)^{*}$ & $1.30(0.05-9.13)^{*}$ & $1.45(0.04-12.55)^{*}$ \\
\hline Self-referral & $0.05(0-0.36)^{*}$ & $0.02(0-0.20)^{*}$ & $0.12(0-2.31) \dagger$ & $0.13(0-3.30) \dagger$ & $0.50(0.01-9.05) \dagger$ & $0.55(0-12.30) \dagger$ & $1.10(0.05-9.13)^{*} \dagger$ & $1.25(0.04-12.55)^{*} \dagger$ \\
\hline Referred by GP & $0.05(0-0.38)^{*}$ & $0.02(0-0.27)^{*}$ & $0.08(0-2.31) \dagger$ & $0.08(0-1.45) \dagger$ & $2.33(0.15-7.52) \dagger$ & $2.25(0.15-10.45) \dagger$ & $2.40(0.22-8.49) \dagger$ & $2.33(0.19-10.55) \dagger$ \\
\hline Private vehicle & $0.06(0-0.38)^{\star} \ddagger$ & $0.02(0-0.27)^{*}$ & $0.14(0-2.31) \ddagger$ & $0.14(0-3.30) \ddagger$ & $0.57(0.01-9.05)^{*} \ddagger$ & $1.06(0-12.30)^{*} \ddagger$ & $1.21(0.05-9.13)^{*} \ddagger$ & $1.38(0.04-12.55)^{*} \ddagger$ \\
\hline Ambulance & $0.00(0-0.30) \ddagger$ & $0.02(0-0.20)$ & $0.00(0-2.31) \ddagger$ & $0.00(0-0.20) \ddagger$ & $2.25(0.11-7.05) \ddagger$ & $2.15(0.05-10.26) \ddagger$ & $2.30(0.11-7.25) \ddagger$ & $2.28(0.09-10.26) \ddagger$ \\
\hline
\end{tabular}


Table 3 After implementation group: median waiting and throughput time, for triaged and non-triaged patients

\begin{tabular}{|c|c|c|c|c|c|c|c|c|}
\hline & nt & $\begin{array}{l}\text { Entrance time } \\
\text { (min-max) }\end{array}$ & $\begin{array}{l}\text { Time to triage } \\
\text { (min-max) }\end{array}$ & $\begin{array}{l}\text { Triage time } \\
\text { (min-max) }\end{array}$ & $\begin{array}{l}\text { Time to treatment } \\
\text { (min-max) }\end{array}$ & $\begin{array}{l}\text { Waiting time } \\
\text { (min-max) }\end{array}$ & $\begin{array}{l}\text { Treatment time } \\
\text { (min-max) }\end{array}$ & $\begin{array}{l}\text { Length of stay } \\
\text { (min-max) }\end{array}$ \\
\hline \multicolumn{9}{|c|}{ Non-triaged } \\
\hline Total & 587 & $0.02(0-0.27)$ & - & - & - & $0.07(0-2.09)^{*}$ & $1.28(0-10.26)^{*}$ & $1.48(0.05-10.26)$ \\
\hline \multicolumn{9}{|l|}{ Triaged } \\
\hline Total & 291 & $0.02(0-0.20)$ & $0.04(0-0.35)$ & $0.04(0.01-0.16)$ & $0.08(0-2.39)$ & $0.20(0-3.30)^{*}$ & $1.08(0.04-12.30)^{*}$ & $1.43(0.12-12.55)$ \\
\hline \multicolumn{9}{|c|}{ Urgency levels } \\
\hline Red & 0 & - & - & - & - & - & - & - \\
\hline Orange & 18 & $0.02(0-0.10)$ & $0.05(0-0.10)$ & $0.06(0.02-0.10)^{*}$ & $0.02(0-0.07)^{*}$ & $0.12(0-0.17)^{*}$ & $2.19(0.15-3.47)^{*}$ & $2.13(0.30-4.04)^{*}$ \\
\hline Yellow & 94 & $0.02(0-0.20)$ & $0.05(0-0.35)$ & $0.05(0.02-0.14)^{*}$ & $0.08(0-0.51)^{*}$ & $0.18(0-1.51)^{*}$ & $2.00(0.07-12.30)^{*}$ & $2.16(0.12-12.55)^{*}$ \\
\hline Green & 172 & $0.02(0-0.15)$ & $0.04(0-0.35)$ & $0.03(0.01-0.16)^{*}$ & $0.11(0-2.39)^{*}$ & $0.22(0-3.30)^{*}$ & $0.51(0.04-10.45)^{*}$ & $1.26(0.14-10.55)^{*}$ \\
\hline Blue & 7 & $0.03(0.1-0.17)$ & $0.05(0.01-0.34)$ & $0.03(0.01-0.05)^{*}$ & $0.11(0.02-1.45)^{*}$ & $0.27(0.09-1.47)^{*}$ & $0.38(0.15-1.23)^{*}$ & $0.59(0.40-1.57)^{*}$ \\
\hline
\end{tabular}

practice. These findings underpin previous research on patients' perceptions of waiting time and LOS, in which perception of waiting time was associated more with satisfaction than actual time did. ${ }^{6} 1517$

The finding that waiting time was longer for triaged patients than for non-triaged patients is counterproductive. The longer waiting time in triaged patients was obviously caused by the triage process itself, but triaging patients resulted in lower treatment time. This suggests that the information obtained from triage, results in a more efficient start of treatment. Furthermore, we quantified the triage time, and showed that the higher the urgency level, the longer it took to triage. We speculate that the higher the urgency, the more time it takes to rule 'no urgency' out.

The strength of this study is that we involved patients to provide additional timeline data, like time to triage as time being triaged. This novel approach to obtain not only routinely sampled data of patients was tested in the before measurement and shows to be accurate. More than $80 \%$ of the differences range from -5 min to 5 min between data provided by patients and routinely sampled data (data not shown).

The Institute of Medicine's Committee on the Future of Emergency Care in the United States Health Systems recommends prioritising improvement of hospital efficiency and patient flow. ${ }^{18}$ From our study, it seems that just simply

Table 4 Number of patients: waiting time and triage to treatment within maximum waiting time by urgency level

\begin{tabular}{lccccc}
\hline $\begin{array}{l}\text { Urgency } \\
\text { level }\end{array}$ & $\begin{array}{l}\text { Maximum } \\
\text { waiting } \\
\text { time }(\mathbf{m i n})^{*}\end{array}$ & $\begin{array}{l}\text { Waiting time } \\
\text { within maximum } \\
\text { waiting time } \mathbf{n}(\%)\end{array}$ & $\begin{array}{l}\mathbf{n} \\
\text { Triage treatment } \\
\text { within maximum } \\
\text { waiting time } \mathbf{n}(\%)\end{array}$ \\
\hline Red & 0 & 0 & - & 0 & - \\
Orange & 10 & 17 & $8(47.1)$ & $14 \dagger$ & $14(100)$ \\
Yellow & 60 & 86 & $81(94.2)$ & $82 \dagger$ & $82(100)$ \\
Green & 120 & 159 & $144(90.6)$ & $148 \dagger$ & $145(98)$ \\
Blue & 240 & 7 & $7(100)$ & 7 & $7(100)$ \\
\hline
\end{tabular}

${ }^{*}$ Maximum waiting time: following Manchester Triage System definitions. ${ }^{11}$ tn differs, because of missing time values for end of triage time.

Triage treatment, time from end triage to entrance of the treatment room; Waiting time, time from registration to entrance of the treatment room. implementing a triage system will not impact this. This is in line with other reviews on effective interventions to improve patient flow. ${ }^{19}{ }^{20}$ For instance, recently two studies on improving EDs by applying the principles of Lean Thinking were published, in which ED processes were changed and an improvement in efficiency was found, like decreased waiting time and LOS. ${ }^{21} 22$ One of the key components of Lean Thinking is the added value to the client (in healthcare, the patient). Overall patient satisfaction was measured in one study only, and was found to have improved. ${ }^{22}$ The principles of Lean Thinking were also applied at our ED in an advanced triage project, in which emergency nurses initiated diagnostic examinations from the triage. A small reduction in LOS for self-referred patients was achieved. ${ }^{23}$ Another recently published study describes the introduction of a new ED care method, in which triage is combined with involvement of a GP in the ED department. This increases patient satisfaction, and led to a $13 \%$ decrease in additional examinations. ${ }^{24}$ These studies suggest that a different architecture of the operating activities can improve the output of that process in terms of efficiency and satisfaction.

\section{LIMITATIONS}

Our study has several limitations. First, by evaluating the implementation of the MTS, we wanted to measure quality improvement. A weakness of this study is the use of a before and after test design, and the relatively long time interval between both measurements. An interrupted time-series design, or a stepped wedge design, would perhaps have been more appropriate and could be used in future research to develop robust evidence on improving the quality of EDs. ${ }^{25}$ Still, we were able to establish a reasonably similar control group.

Second, our study suffered from a mediocre response rate on patient satisfaction. This may have biased the results, but we detected no differences between responders and non-responders. Furthermore, our response rate is comparable with other studies performed at the ED. ${ }^{26}$ A diversity of survey instruments in assessing patient perceptions of hospital care exist, in which response rates range from $17 \%$ to $92 \% .{ }^{27}$ Therefore, we suppose that our results are still valid.

Third, it is preferable that a valid and reliable patient satisfaction questionnaire should be used, but at the performance of this study, none existed. Therefore, we used the literature and 
Table 5 Patient satisfaction

\begin{tabular}{|c|c|c|c|c|c|}
\hline & n Total & Spoken information (\%) & Opportunity to tell complaints (\%) & Time periods (\%) & Problem sorted out (\%) \\
\hline Before implementation group & 356 & & & & \\
\hline Satisfied & & $76.5^{*}$ & $82.1^{*}$ & $26.7^{*}$ & $53.0^{*}$ \\
\hline Fairly satisfied & & 22.1 & 26.2 & 57.0 & 43.6 \\
\hline Not satisfied & & 1.4 & 1.7 & 16.3 & 3.4 \\
\hline After implementation group & 286 & & & & \\
\hline Satisfied & & $61.7^{*}$ & $74.6^{*}$ & $36.6^{*}$ & $71.2^{*}$ \\
\hline Fairly satisfied & & 37.6 & 23.6 & 46.9 & 24.4 \\
\hline Not satisfied & & 0.7 & 1.8 & 16.5 & 4.4 \\
\hline \multicolumn{6}{|l|}{ After implementation group } \\
\hline Not triaged & 188 & & & & \\
\hline Satisfied & & 64.2 & 75.6 & 37.1 & 69.7 \\
\hline Fairly satisfied & & 34.7 & 22.2 & 46.0 & 25.2 \\
\hline Not satisfied & & 1.1 & 2.2 & 16.9 & 5.1 \\
\hline Triaged & 98 & & & & \\
\hline Satisfied & & 56.8 & 72.8 & 35.8 & 74.2 \\
\hline Fairly satisfied & & 43.2 & 26.1 & 48.4 & 22.6 \\
\hline Not satisfied & & 0 & 1.1 & 15.8 & 3.2 \\
\hline \multicolumn{6}{|l|}{ Urgency levels } \\
\hline Green & 57 & & & & \\
\hline Satisfied & & 57.1 & 73.2 & 35.7 & 73.2 \\
\hline Fairly satisfied & & 42.9 & 26.8 & 48.2 & 23.2 \\
\hline Not satisfied & & 0 & 0 & 16.1 & 3.6 \\
\hline Yellow & 30 & & & & \\
\hline Satisfied & & 48.3 & 69.2 & 20.7 & 77.8 \\
\hline Fairly satisfied & & 51.7 & 30.8 & 58.6 & 18.5 \\
\hline Not satisfied & & 0 & 0 & 20.7 & 3.7 \\
\hline
\end{tabular}

Due to the low numbers in the other urgency levels, numbers are not presented.

* Significance level $p<0.05$.

previously used survey measurements to identify the most relevant questions. A Likert scale offers a range of choices from strongly positive to negative. For benchmark activities, we used the same Likert scale as in the previous measurements. For study purposes, the Dutch answer options were translated back and forth in English by a native language speaking physician. Generally, patient responses are biased towards positive choices. To identify quality improvements aspects, we followed the same norm for values as used for benchmarking in the core questionnaire for the assessment of patient satisfaction in academic hospitals in The Netherlands. ${ }^{28}$

Fourth, although we focused on and measured the four most relevant questions on patient satisfaction, a more detailed questionnaire would have given more insight into this aspect. ${ }^{14}{ }^{15} \mathrm{In}$ future research, recently identified consumer expectations, such as information on parking, how an ED works and how to identify staff could be incorporated as satisfaction outcomes. ${ }^{29}$ As a target group, the self-referred and low-urgency patients could be chosen as they are by far the largest groups attending EDs.

Fifth, we used differing methods to distribute the patient satisfaction questionnaire, which may have influenced the results. Patients who fill in a questionnaire immediately after their visit, are often more positive than if they have time to criticise the effectiveness of their visit. Studies on this aspect show that satisfaction declines over time. ${ }^{30}$ Our results showed the same, but overall, the satisfaction scores were higher if the handout questionnaire was used, except for waiting time and the feeling that their problem had been sorted out. This suggests that satisfaction scores regarding waiting time after implementation of the MTS are even higher than our results showed. To overcome the problem of different distribution methods and the time between the before and the after measurement, we performed subanalyses between triaged and non-triaged patients in the after measurement. Differences between these two groups show that, although the 'satisfied' group is somewhat lower in the triaged group, the 'not satisfied' group is decreasing.

\section{CONCLUSION}

In conclusion, implementing MTS on its own is not sufficient to improve the efficiency and quality of EDs. More complex interventions, including process redesigning that targets various groups of ED patients, should be evaluated in the future by using rigorous research designs for quality improvement of EDs.

Acknowledgements The authors thank all employees and patients of the emergency department who contributed to the realisation of this study. Thanks to Sjaak Molenaar for his critical comments on the patients' satisfaction analysis. Thanks also to the English language editor Daphne Lees for checking the manuscript. Furthermore, we are grateful to the members of the study group: ER Schinkel, R Köhlinger and DC Schutte.

Contributors MNS-V: study concept and design; acquisition of the data; analysis and interpretation of the data; drafting of the manuscript; statistical expertise; administrative, technical, or material support. HV: analysis and interpretation of the data; critical revision of the manuscript for important intellectual content; statistical expertise. NvL: acquisition of the data; analysis and interpretation of the data; administrative, technical, or material support. JSKL: study concept and design; analysis and interpretation of the data; critical revision of the manuscript for important intellectual content; study supervision. JCG: analysis and interpretation of the data; critical revision of the manuscript for important intellectual content; study supervision.

Competing interests None. 
Ethics approval The institutional ethics review board waived the requirement for written informed consent.

Provenance and peer review Not commissioned; externally peer reviewed.

\section{REFERENCES}

1 Hoot NR, Aronsky D. Systematic review of emergency department crowding: causes, effects, and solutions. Ann Emerg Med 2008;52:126-36.

2 Collis J. Adverse effects of overcrowding on patient experience and care. Emerg Nurse 2010;18:34-9.

3 Sprivulis PC, Da Silva JA, Jacobs IG, et al. The association between hospital overcrowding and mortality among patients admitted via Western Australian emergency departments. Med J Aust 2006;184:208-12.

4 Bernstein SL, Aronsky D, Duseja R, et al. Society for Academic Emergency Medicine, Emergency Department Crowding Task Force. The effect of emergency department crowding on clinically oriented outcomes. Acad Emerg Med 2009;16:1-10.

5 Fernandes CB, Groth SJ, Johnson LA, et al. A uniform triage scale in emergency medicine. Am Coll Emerg Phys 1999. www.acep.org/WorkArea/DownloadAsset. aspx?id=34332 (accessed 2 Jan 2012).

6 Taylor C, Benger JR. Patient satisfaction in emergency medicine. Emerg Med J 2004;21:528-32.

7 Moore JD, Saywell RM, Thakker N, et al. An analysis of patient compliance with nurse recommendations from an after-hours call center. Am J Manag Care 2002;8:343-51.

8 Brown AD, Sandoval GA, Levinton C, et al. Developing an efficient model to select emergency department patient satisfaction improvement strategies. Ann Emerg Med 2005;46:3-10

9 Cooke T, Watt $D$, Wertzler W, et al. Patient expectations of emergency department care: phase II-across-sectional survey. CJEM 2006;8:148-57.

10 Hill $P$, Kirsch T, DeRugerriero K, et al. Impact of emergency department triage and prebed provider evaluation on walk-out rate, ambulance diversion and patient satisfaction. Acad Emerg Med 2007;14(issue 1):S149.

11 Storm-Versloot MN, Ubbink DT, Chin a Choi V, et al. Observer agreement of the Manchester Triage System and the emergency severity index: a simulation study. Emerg Med J 2009:26:556-60.

12 Storm-Versloot MN, Ubbink DT, Kappelhof J, et al. Comparison of an informally structured triage system, the emergency severity index, and the Manchester Triage System to distinguish patient priority in the emergency department. Acad Emerg Med 2011;18:822-9.

13 Mackway-Jones K. Emergency triage: Manchester Triage Group. London: BMJ Publishing Group, 1997

14 Boudreaux ED, Ary RD, Mandry CV, et al. Determinants of patient satisfaction in a large municipal ED: the role of demographic variables, visit characteristics, and patient perceptions. Am J Emerg Med 2000;18:394-400.
15 Thompson DA, Yarnold PR, Williams DR, et al. Effects of actual waiting time, perceived waiting time, information delivery and expressive quality on patient satisfaction in the emergency department. Ann Emerg Med 1996;28:657-65.

16 Streiner DL, Norman GR. Correction for multiple testing: is there a resolution? Chest 2011;140:16-18

17 Soremekun OA, Takayesu JK, Bohan SJ. Framework for analyzing wait times and other factors that impact patient satisfaction in the emergency department. J Emerg Med 2011:41:686-92.

18 Institute of Medicine. The future of emergency care in the United States health system. 2006. http://www.iom.edu/Activities/Quality/emergencycare.aspx (accessed 2Jan 2012)

19 Oredsson $\mathrm{S}$, Jonsson $\mathrm{H}$, Rognes J, et al. A systematic review of triage-related interventions to improve patient flow in emergency departments. Scand J Trauma Resusc Emerg Med 2011;19:43.

20 Harding KE, Taylor NF, Leggat SG. Do triage systems in healthcare improve patient flow? A systematic review of the literature. Aust Health Rev 2011;35: 371-83.

21 Murrell KL, Offerman SR, Kauffman MB. Applying lean: implementation of a rapid triage and treatment system. West J Emerg Med 2011;12:184-91.

$22 \mathrm{Ng} \mathrm{D}$, Vail G, Thomas S, et al. Applying the lean principles of the Toyota production system to reduce wait times in the emergency department. CJEM 2010;12:50-7.

23 Rosmulder RW, Krabbendam JJ, Kerkhoff $\mathrm{AH}$, et al. 'Advanced triage' improves patient flow in the emergency department without affecting the quality of care. Ned Tijdschr Geneeskd 2010;154:A1109.

24 Boeke AJ, van Randwijck-Jacobze ME, de Lange-Klerk EM, et al. Effectiveness of GPs in accident and emergency departments. Br J Gen Pract 2010;60:e378-84.

25 Fan $\mathrm{E}$, Laupacis $\mathrm{A}$, Pronovost PJ, et al. How to use an article about quality improvement. JAMA 2010;304:2279-87.

26 Santuzzi NR, Brodnik MS, Rinehart-Thompson L, et al. Patient satisfaction: how do qualitative comments relate to quantitative scores on a satisfaction survey? Qual Manag Health Care 2009;18:3-18.

27 Castle NG, Brown J, Hepner KA, et al. Review of the literature on survey instruments used to collect data on hospital patients' perceptions of care. Health Serv Res 2005;40:1996-2017.

28 Kleefstra SM, Kool RB, Veldkamp CM, et al. A core questionnaire for the assessment of patient satisfaction in academic hospitals in The Netherlands: development and first results in a nationwide study. Qual Sad Health Care 2010; 19:e24.

29 Kington $M$, Short AE. What do consumers want to know in the emergency department? Int I Nurs Pract 2010;16:406-11.

30 Gribble RK, Haupt C. Quantitative and qualitative differences between handout and mailed patient satisfaction surveys. Med Care 2005;43:276-81. 